\title{
Answer to the Letter to the Editor relating: Lytvynchuk LM, Falkner-Radler Cl, Krepler K, Glittenberg CG, Ahmed D et al. "Dynamic intraoperative optical coherence tomography for inverted internal limiting membrane flap technique in large macular hole surgery" Graefe's Arch Clin Exp Ophthalmol 2019 May 29; https://doi.org/10.1007/s00417-019-04364-5 written by Michalewska Z. and Nawrocki J.
}

\author{
Lyubomyr M. Lytvynchuk ${ }^{1,2}$ (D) $\cdot$ Susanne Binder ${ }^{2,3,4}$ \\ Received: 30 August 2019 / Revised: 30 August 2019 / Accepted: 5 September 2019 / Published online: 8 October 2019 \\ (C) Springer-Verlag GmbH Germany, part of Springer Nature 2019
}

Dear Editor,

We have read the Letter to the Editor written by Zofia Michalewska and Jerzy Nawrocki relating our manuscript "Dynamic intraoperative optical coherence tomography for inverted internal limiting membrane flap technique in large macular hole surgery" Graefe's Arch Clin Exp Ophthalmol 2019 May 29. Being relatively new technique, inverted ILM flap technique, which was first proposed and described by Michalewska et al., became very popular among vitreoretinal surgeons due to its efficacy and favorable postoperative results [1]. Up until now, the variety of modifications of the technique with the use of ILM flap was proposed [2]. The differences

Lyubomyr M. Lytvynchuk

lyubomyr.lytvynchuk@gmail.com

Susanne Binder

susanne@susannebinder.com

1 Departement of Ophthalmology, Justus Liebig University, University Hospital Giessen and Marburg GmbH, Friedrichstrasse 18, 35392 Giessen, Germany

2 Karl Landsteiner Institute for Retinal Research and Imaging, Juchgasse 25, A-1030 Vienna, Austria

3 Retina Center Vienna, Jacquingasse 41, 1030 Vienna, Austria

4 Department of Ophthalmology, Sigmund Freud University, Eye Center Donaustadt, Zschokkegasse 140, 1220 Vienna, Austria between these technique modifications shall be without any doubt appreciated and well distinguished.

Our study primarily was focused on the use of intraoperative optical coherence tomography (iOCT) for macular surgery and its efficacy, which clearly can contribute to the technical performance of the new techniques and their intraoperative control. The inverted ILM flap technique is one of the newest methods for macular hole surgery, where the value of the microscope-integrated intraoperative OCT use can be fully appreciated. Among the main advantages of the iOCT use are side view imaging of the surgical intervention with assessment of the surgical maneuvers and tissue response, intraoperative control during every step of the surgery and efficacy during the learning curve. The authors are grateful to the developers of the inverted ILM flap technique for this Letter to the Editor, which allows for clarifying the terminological confusions mentioned in our article.

\section{References}

1. Michalewska Z, Michalewski J, Adelman RA, Nawrocki J (2010) Inverted internal limiting membrane flap technique for large macular holes. Ophthalmology 117:2018-2025

2. Singh SR, Hariprasad SM, Narayanan R (2019) Current management of macular hole. Ophthalmic Surg Lasers Imaging Retina 50(2):61-68. https://doi.org/10.3928/23258160-20190129-01

Publisher's note Springer Nature remains neutral with regard to jurisdictional claims in published maps and institutional affiliations. 